\title{
MAPEAMENTO DA SUSCETIBILIDADE A OCORRÊNCIAS DE INCÊNDIOS EM VEGETAÇÃO NA ÁREA URBANA DE UBÁ-MG ${ }^{1}$
}

\author{
Fillipe Tamiozzo Pereira Torres², Guido Assunção Ribeiro³, Sebastião Venâncio Martins ${ }^{3}$ e Gumercindo
} Souza Lima ${ }^{3}$

\begin{abstract}
RESUMO - O fogo é problema crescente nos diferentes tipos de formação vegetal em diversas partes do mundo. Apesar de anos de estudo científico e de toda atenção da mídia em relação aos incêndios em vegetação, os efeitos que tais fenômenos causam no ambiente não são completamente conhecidos, e as ferramentas de controle são pouco acessíveis a grande parte dos usuários. É fundamental saber o que condiciona as ocorrências, o que favorece a dispersão do fogo e o padrão de tais ocorrências, para possibilitar o mapeamento das áreas de risco e permitir o desenvolvimento de programas específicos para as regiões críticas. O objetivo deste estudo foi produzir um mapa de suscetibilidade a incêndios em vegetação, dentro do perímetro urbano do Município de Ubá, MG, com a utilização de informações referentes ao relevo, ao uso e cobertura do solo e à proximidade de vias de acesso e áreas urbanas, empregando técnicas de Geoprocessamento. A partir da validação do cartograma gerado, observou-se que $80 \%$ das ocorrências têm-se localizado nas áreas de alto e altíssimo risco, 15\% nas de médio risco e 5\% nas áreas de baixo e baixíssimo risco. Esse mapeamento servirá como ferramenta para o poder público estabelecer políticas de prevenção, atuando na conscientização da população e na definição de medidas de controle nas áreas de maior risco.
\end{abstract}

Palavras-chave: Incêndios em vegetação; Suscetibilidade; Mapa.

\section{SUSCEPTIBILITY MAPPING OF THE OCCURRENCE OF VEGETATION FIRE IN THE URBAN AREA OF UBÁ - MG}

\begin{abstract}
Fire is a growing problem in the different types of vegetation around the world. Despite years of scientific study and all the media attention in relation to forest fires, the effects they cause to the environment are not completely known, and the control tools are little accessible to most of the users. It is essential to know what is the cause of the fires, what makes the fire dispersion easier and the patterns of such fires to enable the mapping of the risk areas and allow the development of specific programs for these regions. Thus, the aim of this study was to produce a map of susceptibility of fires in vegetation within the urban perimeter of Ubá (MG), with the use of information related to relief and the use and land cover and proximity of access roads and urban areas, through geoprocessing techniques. From the validation of the generated cartogram, it was observed that $80 \%$ of the cases were located in areas of high and very high risk, 15\% in medium risk and 5\% in areas of low and very low risk. This mapping will serve as a tool for the government to establish prevention policies, operating in the public awareness and control measures definition in the higher risk areas.
\end{abstract}

Keywords: Vegetations fires; Susceptibility; Map.

\footnotetext{
${ }^{1}$ Recebido em 14.11.2013 aceito para publicação em 04.07.2014.

${ }^{2}$ Programa de Pós-Graduação em Ciências Florestais, Universidade Federal de Viçosa, UFV, Brasil. E-mail: <torresftp@yahoo.com.br>.

${ }^{3}$ Departamento de Engenharia Florestal, Universidade Federal de Viçosa, Brasil. E-mail: <gribeiro@ufv.br>, <venancio@ufv.br> e<gslima@ufv.br>.
} 


\section{INTRODUÇÃO}

Nas últimas décadas, a maior parte dos incêndios foi observada em ecossistemas tropicais queimando milhões de hectares, com milhões de dólares de prejuízos econômicos e impactos para a saúde de milhares de pessoas em vários países. Apesar disso, os efeitos que esse fenômeno causa ao ambiente ainda têm sido ignorados (COCHRANE, 2009).

Para Fiedler et al. (2006), os incêndios em vegetação podem ocorrer em Unidades de Conservação, áreas de preservação, fazendas, margens de estradas, proximidades de aglomerados urbanos e áreas de reflorestamento, entre outras localidades.

Os incêndios ocorrem quando alguns fatores associados à combustão e propagação do fogo tornam-se favoráveis à ignição e à propagação das chamas (NOGUEIRA et al., 2002).

Há dois tipos de fatores determinantes do grau de perigo de incêndio: os fatores constantes, representados pelo tipo de material combustível, que reflete os diferentes tipos de vegetação e o relevo (sobretudo através da declividade e exposição das vertentes ao sol); e os fatores variáveis, representados pelas condições atmosféricas (TORRES et al., 2011).

Por conta da facilidade de espacialização dos fatores constantes, estes se tornam de grande valia para o estabelecimento de mapas de suscetibilidade à ocorrência de incêndios, denominados por Batista (2000) como zoneamento de risco ou de mapas de risco de incêndios. Segundo esse autor, essa ferramenta tem sido empregada com muita eficiência como instrumento para o planejamento racional dos recursos, visando à prevenção e à pré-supressão dos incêndios em vegetação. Para Soares e Santos (2002), é fundamental saber onde ocorrem os incêndios para determinação das áreas de maior risco, estabelecendo programas específicos para essas regiões.

O uso de ferramentas ligadas ao Sistema de Informações Geográficas (SIG), de acordo com Faria et al. (2003), permite obter mapas com rapidez e precisão a partir da atualização dos bancos de dados, sendo ferramenta importante no estudo de potencialidades do ambiente, onde os cartogramas gerados fornecem uma visão sobre diversos componentes, como a declividade, o uso e a cobertura, os solos, a geomorfologia, entre outros, além de possibilitar o intercruzamento dos mapas gerados, estimando áreas de risco, potenciais ambientais e definindo zoneamentos.

Diante do exposto, o objetivo deste estudo foi produzir um mapa de suscetibilidade a incêndios em vegetação, dentro do perímetro urbano do Município de Ubá, MG, com a utilização de informações referentes ao relevo, ao uso e cobertura do solo e às proximidades de vias de acesso e de edificações. O cartograma gerado servirá como ferramenta para o poder público estabelecer políticas de prevenção, atuando na conscientização da população e com medidas de controle nas áreas de maior risco.

\section{MATERIAL E MÉTODOS}

O Município de Ubá situa-se na mesorregião fisiográfica denominada Zona da Mata mineira. Encontra-se entre as latitudes de $21^{\circ} 16^{\prime}$ a $20^{\circ} 57^{\prime}$ 'Sul e as longitudes de $43^{\circ} 07^{\prime}$ a $42^{\circ} 57^{\prime}$ Oeste. Sua extensão é de aproximadamente 40.750 ha, e sua população foi determinada pelo IBGE (2010) em 101.466 habitantes.

A região apresenta, predominantemente em seu relevo, áreas de declividade ondulada forte, compreendendo cerca de 16.556 ha, o que representa 40,6\% do seu território; outros 11.354 ha, correspondendo a $27,9 \%$, podem ser considerados planos; e 8.790 ha ou 21,6\% possuem topografia intermediária. Os 8,9\% restantes do município apresentam estrutura montanhosa (TORRES et al., 2010a).

A elaboração do cartograma de suscetibilidade a incêndios no perímetro urbano foi feita a partir do software ArcGIS 10.1, com a geração dos mapas de Declividade, de Exposição das Vertentes e de Uso e Ocupação do Solo. Esses mapas foram intercruzados, possibilitando a determinação das áreas mais suscetíveis aos incêndios.

A confecção dos mapas de declividade e de exposição das vertentes foi possível com a produção de um Modelo Digital de Elevação (MDE), quando foram interpoladas as curvas de nível de 10-10 m, extraídas das imagens aéreas ortorretificadas na escala de 1:10.000, de novembro de 2005.

O mapa de uso do solo foi originado a partir da interpretação visual das imagens aéreas ortorretificadas, quando foram vetorizadas as seguintes classes de uso do solo no perímetro urbano do município: mata, capoeira, 
pastagem, agricultura, tanques/lagos, solo exposto e área construída. A confiabilidade dos dados e a validação da classificação realizada em laboratório foi conferida a partir da coleta de pontos georreferenciados em campo, utilizando GPS.

Após a geração dos cartogramas alusivos à Declividade, Exposição das Vertentes e de Uso e Ocupação do Solo, foram analisadas as classes referentes a cada um desses mapas, atribuindo notas a cada classe, de acordo com o favorecimento à ocorrência de incêndios (Tabela 1), em que 0 significa que o risco é nulo e 10, altíssimo.

As notas utilizadas foram embasadas nos estudos de Torres et al. (2008, 2010a), que estudaram o perfil dos incêndios em vegetação nos Municípios de Ubá e Juiz de Fora, ambos localizados na Zona da Mata mineira.

A partir da reclassificação dos mapas com as respectivas notas, esses foram intercruzados (através da multiplicação das notas atribuídas a cada classe), com pesos diferentes descritos a seguir, como mostrado na árvore de decisão da Figura 1.

O cartograma de Uso do Solo foi cruzado com a Exposição das Vertentes, ambos com pesos iguais, gerando o que se denominou facilidade de ignição. Esse cartograma representou peso de $66 \%$ quando cruzado com a declividade (peso 34\%), gerando a facilidade de propagação. Sobre esse cartograma foram sobrepostas as proximidades às vias de acesso e às áreas edificadas, criando um buffer de $15 \mathrm{~m}$ ao seu redor.

Os valores obtidos por esse intercruzamento variaram de 0 a 3.144.000, sendo agrupados em seis classes de risco: Nulos, com produto igual a 0;
Baixíssimos, de 1 a 450.000; Baixos, de 450.001 a 900.000; Médios, de 900.001 a 1.250.000; Altos, de 1.250.001 a 1.700.000; e Altíssimos, acima de 1.700.000.

A análise da eficácia do cartograma gerado (incluindo o agrupamento dos valores atribuídos a cada classe de risco) e da influência dos fatores estudados sobre a ocorrência de incêndios foi feita com o uso de 732 registros de ocorrências, disponibilizadas pelo Corpo de Bombeiros ( $3^{\mathrm{a}}$ Cia. BM), sediada em Ubá. Foram tabuladas as coordenadas de cada ocorrência e, posteriormente, lançadas sobre o mapa de suscetibilidade gerado para checagem da influência dos componentes ambientais e das infraestruturas (proximidades) na origem dos incêndios.

\section{RESULTADOS}

Os cartogramas produzidos para geração do mapa final são mostrados na Figura 2.

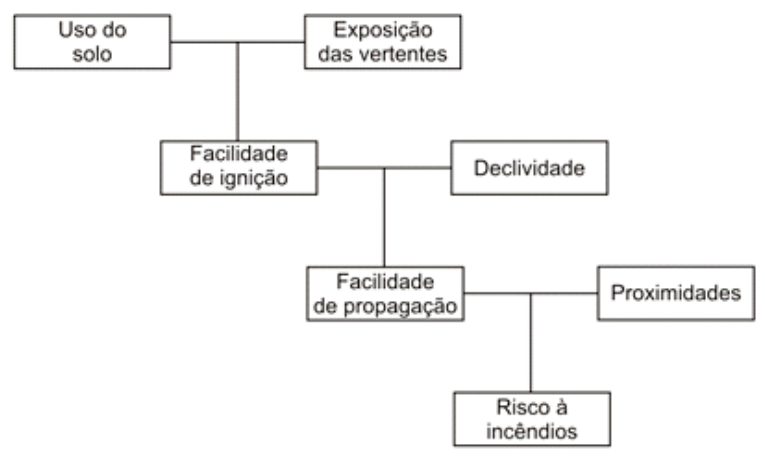

Figura 1 - Árvore de decisão de riscos a incêndios. Figure 1-Decision tree of fire risk.

Tabela 1 - Tabela de notas do mapa de risco de incêndios na área urbana de Ubá, MG.

Table 1 - Table of notes of the map of fire risk in the urban area of Ubá, MG.

\begin{tabular}{|c|c|c|c|c|c|}
\hline \multicolumn{2}{|c|}{ Uso do solo } & \multicolumn{2}{|c|}{ Exposição das vertentes } & \multicolumn{2}{|c|}{ Declividade } \\
\hline Classe & $\overline{\text { Notas }}$ & Classe & $\overline{\text { Notas }}$ & Classe & $\overline{\text { Notas }}$ \\
\hline Área construída & 0 & Sul $\left(135^{\circ}\right.$ a $\left.225^{\circ}\right)$ & 4 & $0^{\circ}$ a $10^{\circ}$ & 2 \\
\hline Solo exposto & 0 & Leste $\left(45^{\circ}\right.$ a $\left.135^{\circ}\right)$ & 6 & $10^{\circ}$ a $20^{\circ}$ & 4 \\
\hline Corpos hídricos & 0 & Oeste $\left(225^{\circ}\right.$ a $\left.315^{\circ}\right)$ & 8 & $20^{\circ}$ a $30^{\circ}$ & 6 \\
\hline Mata & 3 & Norte $\left(0^{\circ}\right.$ a $\left.45^{\circ}\right)$ & 10 & $30^{\circ}$ a $40^{\circ}$ & 8 \\
\hline Agricultura & 5 & Norte $\left(315^{\circ}\right.$ a $\left.360^{\circ}\right)$ & 10 & $>40^{\circ}$ & 10 \\
\hline Capoeira & 7 & & & & \\
\hline Pasto & 10 & & & & \\
\hline
\end{tabular}

Fonte: Adaptado de TORRES et al., 2008, 2010a.

Source: Adapted from TORRES et al., 2008, $2010 a$.

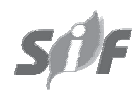

Revista Árvore, Viçosa-MG, v.38, n.5, p.811-817, 2014 


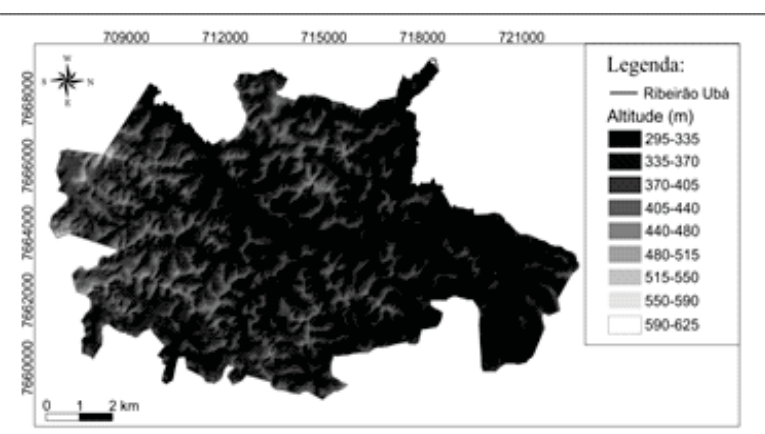

$1 \mathrm{~A}$ - Modelo digital de elevaçào
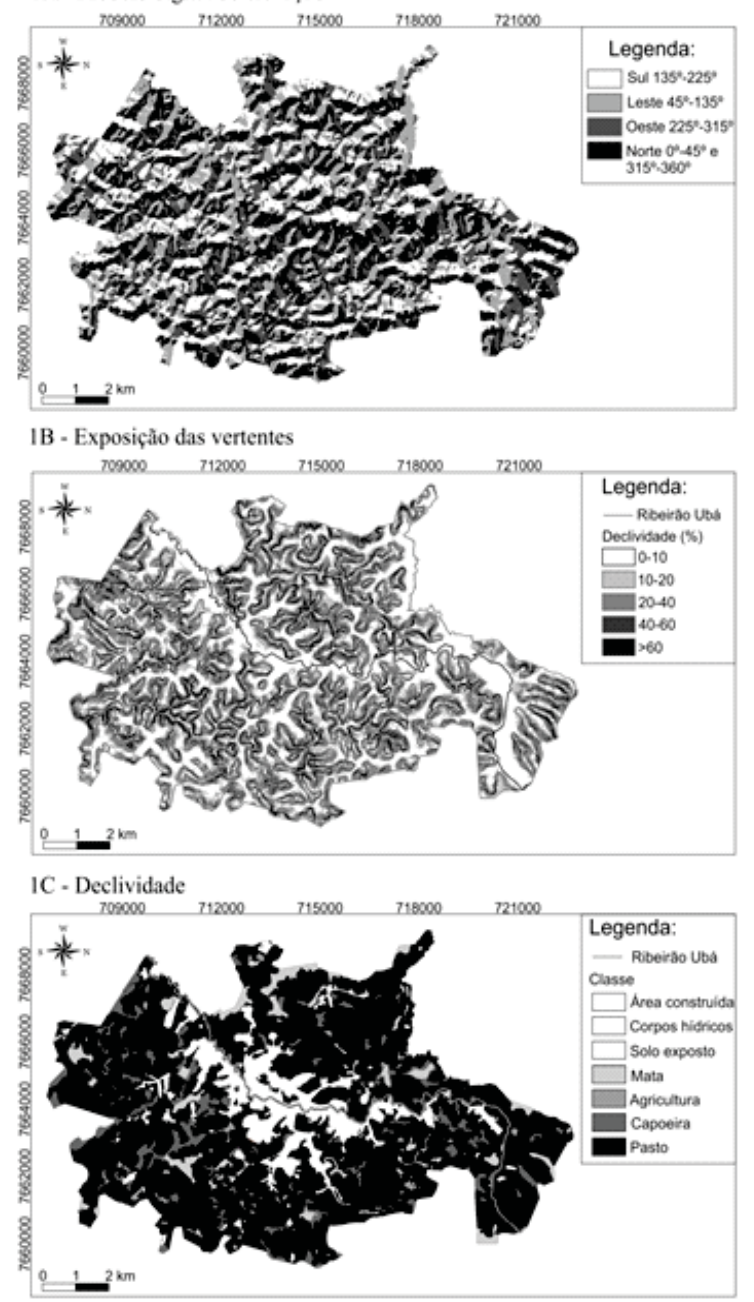

1D - Uso do solo

Figura 2 - Cartogramas utilizados para geração do cartograma de suscetibilidade a incêndios na área urbana de Ubá, MG

Figure 2-Cartograms used to generate the cartogram of fire susceptibility in the urban area of Ubá, MG.
Analisando a exposição das vertentes das ocorrências, observou-se a concentração de maior número de incêndios nas vertentes voltadas para o Norte (43\%), seguidas das vertentes para Oeste (27\%), Leste (18\%) e Sul (12\%), apresentando menor número de ocorrências.

Com relação à declividade, $2 \%$ dos eventos ocorreram com declividade entre $0^{\circ}$ e $10^{\circ}, 6 \%$ de $10^{\circ}$ a $20^{\circ}, 22 \%$ de $20^{\circ}$ a $30^{\circ}, 26 \%$ de $30^{\circ}$ a $40^{\circ}$ e $44 \%$ em áreas com declividade superior a $40^{\circ}$.

A distribuição das ocorrências de acordo com o uso do solo foi: $89,37 \%$ em pastos, 9,13\% em capoeiras, 0,84\% em matas e 0,56\% em áreas de agricultura (incluindo florestas plantadas).

O cartograma de suscetibilidade a incêndios em vegetação resultante está mostrado na Figura 3. As extensões das áreas de cada uma das classes de risco, bem como a porcentagem das ocorrências de acordo com essas extensões, são mostradas na Tabela 2.

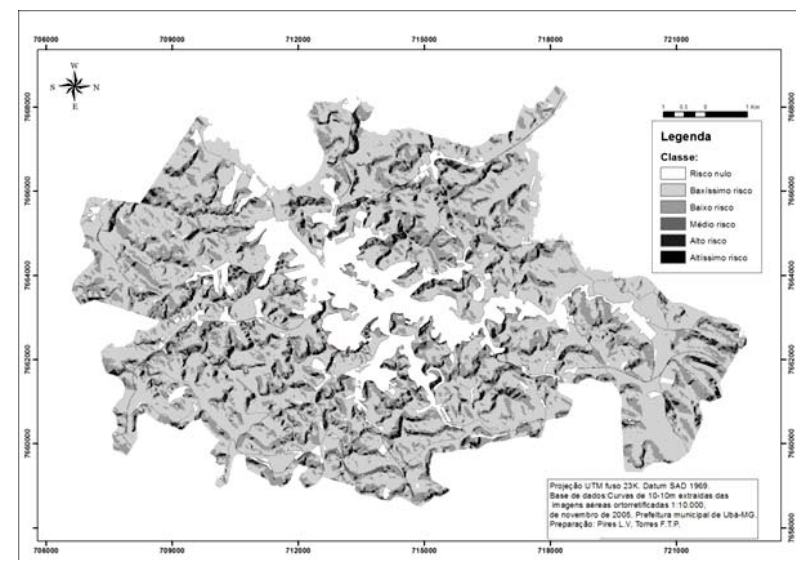

Figura 3-Cartograma de suscetibilidade a incêndios em vegetação na área urbana de Ubá MG.

Figure 3 - Cartogram of vegetation fire susceptibility in the urban area of Ubá, MG.

Tabela 2 - Porcentagem da área e de ocorrências por classe de risco na área urbana de Ubá, MG.

Table 2 - Percentage of area and events by risk class in the urban area of Ubá, $M G$.

\begin{tabular}{ccc}
\hline Classe de risco & \% da área & \% de ocorrências \\
\hline Nulo & 13,7 & 0 \\
Baixíssimo & 49,8 & 1 \\
Baixo & 26,5 & 4 \\
Médio & 3,1 & 15 \\
Alto & 5,9 & 28 \\
Altíssimo & 1,0 & 52 \\
\hline
\end{tabular}

Revista Árvore, Viçosa-MG, v.38, n.5, p.811-817, 2014 


\section{DISCUSSÃO}

Os resultados indicaram como os fatores estudados (exposição da vertente, declividade e uso do solo) podem facilitar o acesso, propagação e extensão da queima ou, mesmo, o comportamento do fogo.

A topografia, segundo Batista (2000), altera as condições climáticas locais e influi no tipo de combustível de uma região. Como o comportamento do fogo é, em grande parte, definido pelo clima e pelo combustível disponível, pode-se concluir que a topografia também influi decisivamente no comportamento do fogo, por esse motivo e pela influência física sobre a inclinação das chamas, aumentando exponencialmente a fase de pré-aquecimento da reação da combustão. Esse fato é confirmado por Ribeiro et al. (2008), quando afirmaram que a propagação do fogo nas áreas de aclive é maior devido ao superaquecimento do material combustível, acima da frente da linha de fogo, pela maior proximidade das chamas, em comparação com os terrenos planos. Se existe um mínimo de declividade, a taxa de propagação tende a crescer e será tanto maior quanto maior forem as transformações microclimáticas na zona de combustão.

Superfícies com orientações e inclinações diferentes recebem quantidades desiguais de radiação solar global em comparação com uma superfície horizontal, em uma mesma localidade e época do ano (TORRES; MACHADO, 2011), influenciando na secagem dos diferentes tipos de material combustível, em cada vertente e, ou, inclinação.

Além desses fatores, Viegas (2004) acrescentou que a propagação do fogo em locais com alguma declividade tem comportamento distinto daquele que ocorre em áreas sem declividade em função do efeito de fatores adicionais, como a convecção e a radiação, que, apesar de também atuarem em áreas planas, em áreas inclinadas aceleram o alastramento do fogo.

Em conjunto com o relevo, o material combustível é determinante na ocorrência de fogo. $\mathrm{O}$ tipo de material combustível e o seu arranjo facilitam a ignição e propagação do fogo. O material fino, por exigir menor temperatura de ignição e perder umidade mais rapidamente (BEUTLING, 2005), facilita o início do incêndio e acelera sua propagação. Essa situação é potencializada quando ocorrem, ainda, distribuição uniforme e maior proximidade das partículas do material combustível, propiciando a propagação do fogo em áreas de pastagens e de lotes vagos, normalmente forrados por gramíneas.

As florestas, ou matas, segundo Torres e Machado (2011), interceptam, entretanto, a radiação solar, reduzindo a temperatura do ar e do material combustível no piso da floresta. Também, funcionam como barreira, evitando a livre passagem de correntes de ar, o que reduz a velocidade do vento. Isso diminui a evaporação, dificultando a secagem do material combustível. Além disso, a transpiração do material florestal proporciona aumento da umidade relativa do ar na área florestada.

Não basta, entretanto, que os fatores diretamente associados à ocorrência dos incêndios florestais estejam favoráveis à ignição inicial e à propagação do fogo. A situação de vulnerabilidade pode permanecer por longo período de tempo porque, para que um incêndio ocorra, é necessária à chama inicial para dar início à reação da combustão.

Diversos autores, como Soares e Cordeiro (1974), Soares e Santos (2002), Bonfim et al. (2003), Santos et al. (2006) e Torres et al. (2010b), afirmaram que a principal causa dos incêndios florestais no Brasil é a atividade antrópica no meio rural, representada por diferentes tipos de comportamento, que vão de um simples descuido com o uso do fogo até o seu uso doloso. Com base nisso, áreas próximas às vias públicas e aglomerações urbanas tendem a ser mais suscetíveis ao início de ocorrências de fogo.

Corroborando esses autores, observou-se, neste trabalho, que as áreas de maior número de ocorrências se concentram próximas a áreas urbanas. Em estudos conduzidos por Torres et al. (2008, 2011), foi identificado que, apesar do cenário apresentado pelo ambiente físico (declividade, exposição das vertentes, uso e ocupação do solo), sem o agente causador (em sua maioria antrópico) não há ocorrência de incêndio. Em qualquer área, seja ela classificada como de altíssimo ou de baixíssimo risco, o evento só ocorrerá a partir da causa ou de uma fonte inicial de calor. Assim, qualquer ação para prevenção dos incêndios florestais deve buscar a eliminação de suas causas (NOGUEIRA et al., 2002).

Revista Árvore, Viçosa-MG, v.38, n.5, p.811-817, 2014 
Com relação à porcentagem de ocorrências por classe de risco, os resultados foram semelhantes aos de Coura et al. (2009), com relação à cidade do Rio de Janeiro. O cruzamento dos cartogramas de geomorfologia, a exposição das vertentes e o uso do solo apresentaram $79 \%$ de acerto na categoria "alta suscetibilidade", 16\% na "média suscetibilidade" e $5 \%$ na "baixa suscetibilidade".

\section{CONCLUSÕES}

De acordo com os resultados, concluiu-se que:

- As notas e pesos utilizados produziram um cartograma que reflete, satisfatoriamente, a suscetibilidade a incêndios na área de estudo.

- As áreas com exposição Norte, maior declividade e próximas às vias de acesso representaram as maiores suscetibilidades às ocorrências.

- A maior parte das áreas classificadas como de “altíssimo risco", bem como a maioria das ocorrências de incêndios no entorno da mancha urbana e das vias de acesso, reflete a importância da atividade antrópica nos eventos.

- O cartograma de suscetibilidade gerado pode servir como instrumento de auxílio à elaboração de estratégias de combate aos incêndios no município.

- A metodologia em foco mostra-se simples e passível de utilização em outras áreas com a mesma problemática.

\section{REFERÊNCIAS}

BONFIM, V. R.; RIBEIRO, G. A.; SILVA, E. Diagnóstico do uso do fogo no entorno do Parque Estadual da Serra do Brigadeiro (PESB), MG. Revista Árvore, v.27, n.1, p.87-94, 2003.

BATISTA, A. C. Mapas de risco: uma alternativa para o planejamento de controle de incêndios florestais. Floresta, v.30, n.1, p.45-54, 2000.

BEUTLING, A. Caracterização para modelagem de material combustível superficial em reflorestamentos de Araucaria angustifolia (Bert.) $O$. Ktze. 2005. 113f. Dissertação (Mestrado em Ciências Florestais) - Universidade Federal do Paraná, Curitiba, 2005.

Revista Árvore, Viçosa-MG, v.38, n.5, p.811-817, 2014
COCHRAnE, M. A. Tropical fire ecology:

climate change, land use, and ecosystem dynamics. Chichester: Springer-Praxis, 2009.

COURA, P. H. F.; SOUSA, G. M.; FERNANDES, M. C. Mapeamento geoecológico da susceptibilidade à ocorrência de incêndios no Maciço da Pedra Branca, município do Rio de Janeiro. Anuário do Instituto de

Geociências - UFRJ, v.32, n.2, p.14-25, 2009.

FARIA, A. L. L.; SILVA, J. X.; GOES, M. H. B. Análise ambiental por geoprocessamento em áreas com susceptibilidade à erosão do solo na bacia hidrográfica do Ribeirão do Espírito Santo, Juiz de Fora (MG). Caminhos de Geografia, v.4, n.9, p.50-65, 2003.

FIEDLER, N. C. et al. Avaliação das condições de trabalho, treinamento, saúde e segurança de brigadistas de combate a incêndios florestais em unidades de conservação do Distrito Federal: estudo de caso. Revista Árvore, v.30, n.1, p.55-63, 2006.

INSTITUTO BRASILEIRO DE GEOGRAFIA E ESTATÍSTICA - IBGE. Censo Demográfico 2010. Rio de Janeiro: 2010.

NOGUEIRA, G. S. et al. Escolha de locais para instalação de torres de detecção de incêndio com auxílio do SIG. Revista Árvore, v.26, n.3, p.363-369, 2002.

SANTOS, J. F.; SOARES, R. V.; BATISTA, A. C. Evolução do perfil dos incêndios florestais em áreas protegidas no Brasil, de 1993 a 2002. Floresta, v.36, n.1, p.93-100, 2006.

SOARES, R. V.; CORDEIRO, L. Análise das causas e épocas de incêndios florestais na região centroparanaense. Floresta, v.5, n.1, p.46-49, 1974.

SOARES, R. V.; SANTOS, J. F. Perfil dos incêndios florestais no Brasil de 1994 a 1997. Floresta, v.32, n.2, p.219-232, 2002.

RIBEIRO, L. et al. Zoneamento de riscos de incêndios florestais para a fazenda experimental do Canguiri, Pinhais (PR). Floresta, v.38, n.3, p.561-572, 2008. 
TORRES, F. T. P. et al. Incêndios em vegetação na área urbana de Juiz de Fora: Minas Gerais. Ubá: Geographica, 2008. 80p.

TORRES, F. T. P. et al. Perfil dos Incêndios em Vegetação nos Municípios de Juiz de Fora e Ubá, MG, de 2001 a 2007. Floresta e Ambiente, v.17, n.2, p.83-89, 2010a.

TORRES, F. T. P. et al. Determinação do período mais propício às ocorrências de incêndios em vegetação na área urbana de Juiz de Fora, MG. Revista Árvore, v.34, n.2, p.297-303, 2010b.

TORRES, F. T. P. et al. Correlações entre os elementos meteorológicos e as ocorrências de incêndios florestais na área urbana de Juiz de Fora, MG. Revista Árvore, v.35, n.1, p.143-150, 2011.

TORRES, F. T. P.; MACHADO, P. J. O. Introdução à climatologia. São Paulo: Cengage Learning, 2011. 280p.

VIEGAS, D. X. Cercados pelo fogo. Coimbra: Minerva, 2004. 283p. 